\title{
Urinary excretion of pyridinium crosslinks of collagen in patients with osteoporosis and the effects of bone fracture
}

\author{
A M McLaren, L D Hordon, H A Bird, S P Robins
}

\begin{abstract}
Values for the urinary excretion of pyridinium crosslinks of collagen, pyridinoline and deoxypyridinoline, in a group of 30 elderly women with femoral fractures associated with osteoporosis and a group of 20 women without recent fracture but with overt or suspected osteoporosis were compared with 27 control subjects matched for age. Relative to the control group, the excretion of the crosslinks was significantly higher in the group with fractures and the group with osteoporosis. Fractures contributed markedly to the excretion of pyridinium crosslinks as the patients with fractures showed significantly higher excretion of pyridinoline and deoxypyridinoline than the group without recent fractures. This was confirmed by the fact that excretion of pyridinium crosslinks in patients with accidental bone fractures was significantly higher than for healthy control subjects matched for age and sex. The crosslinks appear to provide valid indices of bone resorption, but the effects of bone fracture must be considered in the clinical application of this technique.
\end{abstract}

Following the recognition that osteoporosis is a major health problem for the aging population in developed countries, considerable attention has been focused on devising methods to measure bone loss and assess the risk of osteoporotic fracture. In addition to static measurements of the mineral content of bones and estimation of bone loss using photon or $x$ ray absorptiometry, analyses of biochemical indices of the rates of bone resorption and formation have been made. For bone resorption, several markers, including urinary hydroxyproline ${ }^{1-3}$ and hydroxylysine glycosides, ${ }^{245}$ have been investigated, but interference resulting from the breakdown of collagen precursors or from other proteins containing collagen-like sequences has limited their use as specific markers of the degradation of bone tissues. ${ }^{6}$

In attempting to develop improved markers of collagen degradation, we investigated the use of the pyridinium crosslinks pyridinoline and deoxypyridinoline. These compounds are trifunctional crosslinks formed by the lysyl oxidase mediated system during the maturation of collagens. $^{7-9}$ Pyridinoline is present predominantly in articular cartilage and to a lesser extent in bone, ${ }^{8}{ }^{10}$ whereas deoxypyridinoline is most abundant in mineralised tissues such as bone and dentine. ${ }^{1011}$ During the process of collagen turnover the two crosslinks are released into the blood and are subsequently excreted in urine. ${ }^{12} 13$

Methods have been developed to quantify these crosslinks in urine ${ }^{13} 14$ and several studies have suggested that these assays could provide indices of cartilage and bone breakdown in patients with arthritic diseases ${ }^{15-17}$ and metabolic bone disorders. ${ }^{18} 19$

In this study, the excretion of pyridinium crosslinks in patients with osteoporosis and osteoporotic bone fractures has been examined in comparison with patients with accidental bone fractures to evaluate the crosslinks as markers of bone resorption and to assess the effects of fractures.

\section{Patients and methods}

The excretion of pyridinium crosslinks was measured in three groups of women.

The first group consisted of 30 patients (aged 69-92 years) with femoral neck fractures associated with severe osteoporosis. Eighteen patients in this group also had an operation either on the day of fracture or up to six days after the fracture. The operation was to insert plates or pins into the fractured bone. None of these patients had pathological fractures as judged by radiological examination. Urine samples were collected from this group between one and 184 days after the fracture. Twelve of the patients had also had previous fractures.

The second group consisted of 20 patients (aged 71-99 years) without recent femoral fracture but with overt or suspected osteoporosis. This classification was based either on the occurrence of vertebral, Colles' or femoral fractures between one and 20 years previously (eight patients) or because of long term steroid treatment (three patients) or severe immobility. A number of these patients had various cardiac and cardiovascular diseases but only two had signs of osteoarthritis.

The third group was 27 control subjects (aged 70-90 years) matched for age who had no history of bone disease.

To assess the effect of fracture alone, crosslink excretion was measured in two groups of men. The first group consisted of 15 patients (aged 20-40 years) with accidental fractures. These were generally single fractures of the femur or tibia, but occasionally multiple fractures of the long bones. None of these patients had known bone disease. Six of the patients underwent an operation to insert plates and pins into the fractured bones; urine samples were collected between one and 227 days after the fractures occurred. 
The second group was 63 control subjects (aged 21-40 years) with no fractures. One or two spot urine samples were collected from each subject and were stored at $-20^{\circ} \mathrm{C}$ until analysis.

Most of the urine specimens in this study were collected as first morning samples. A detailed investigation of diurnal variations has shown that in healthy volunteers and patients the crosslink concentrations in the morning are $10-15 \%$ higher than the 24 hour mean value expressed relative to creatinine (McLaren et al, unpublished results).

\section{ANALYTICAL PROCEDURES}

The concentrations of pyridinoline and deoxypyridinoline in the hydrolysed urine samples were determined by high performance liquid chromatography as described previously ${ }^{14}$ except that heptafluorobutyric acid (Pierce, Cambridge, UK) was used as the ion pair reagent instead of octanesulphonic acid. ${ }^{17}$ The results were expressed as nmol crosslink per

Table 1 Excretion of hydroxypyridinium crosslinks (Pyd=pyridinoline; Dpd= deoxypyridinoline) in urine from patients with osteoporosis compared with healthy controls. Values are mean $(S D)$ expressed relative to creatinine

\begin{tabular}{|c|c|c|c|c|}
\hline \multirow[t]{2}{*}{$\begin{array}{l}\text { Group } \\
\text { of patients }\end{array}$} & \multirow{2}{*}{$\begin{array}{l}\text { Mean age } \\
\text { (range) } \\
\text { (years) }\end{array}$} & \multicolumn{2}{|c|}{$\begin{array}{l}\text { Mean }(S D) \text { concentration } \\
\text { (nmol/mmol creatinine })\end{array}$} & \multirow[t]{2}{*}{$\begin{array}{l}\text { Pyd/Dpd } \\
\text { ratio }\end{array}$} \\
\hline & & Pyd & Dpd & \\
\hline Severe osteoporosis with fracture $(n=30)$ & $\begin{array}{l}82 \\
(69-92)\end{array}$ & $172 \cdot 6(94 \cdot 7)$ & $39 \cdot 3(21 \cdot 5)$ & $4.5(1.0)$ \\
\hline Osteoporosis without fracture $(n=20)$ & $\begin{array}{l}86 \\
(71-99)\end{array}$ & $99 \cdot 2(57 \cdot 0)$ & $24 \cdot 3(11 \cdot 0)$ & $4.0(0.9)$ \\
\hline Healthy control subjects $(n=27)$ & $\begin{array}{l}78 \\
(70-90)\end{array}$ & $44 \cdot 5(10 \cdot 6)$ & $10 \cdot 2(2 \cdot 5)$ & $4.5(0.8)$ \\
\hline
\end{tabular}

mmol creatinine, the latter being measured in aliquots of unhydrolysed urine. ${ }^{20}$

The statistical significance of differences between the patient groups and control subjects was determined by Student's $t$ test using the Minitab program.

\section{Results}

The figure gives the values of pyridinoline and deoxypyridinoline excretion relative to creatinine for patients with femoral fractures or osteoporosis compared with those for the control subjects matched for age. The patients with fractures showed significantly higher excretion of pyridinoline $(p<0.001)$ and deoxypyridinoline $(p<0.01)$ than the group without recent fractures. The excretion of crosslinks was also significantly higher in the patients with fractures $(\mathrm{p}<0.001)$ and osteoporosis $(\mathrm{p}<0.05)$ compared with the control subjects (table 1). The molar ratio pyridinoline/deoxypyridinoline was not significantly different between the three groups.

Within the fracture group there was no significant difference in the excretion of pyridinium crosslinks or the pyridinoline/ deoxypyridinoline ratio of crosslinks between the patients who had or did not have an operation (table 2).

Table 3 shows that the excretion of pyridinium crosslinks in patients with accidental bone fractures was significantly higher $(p<0.001)$ than that for the healthy control group matched for age. There was no significant difference in the pyridinoline/deoxypyridinoline ratio in urine between the accidental fracture group and the control subjects (table 3 ).

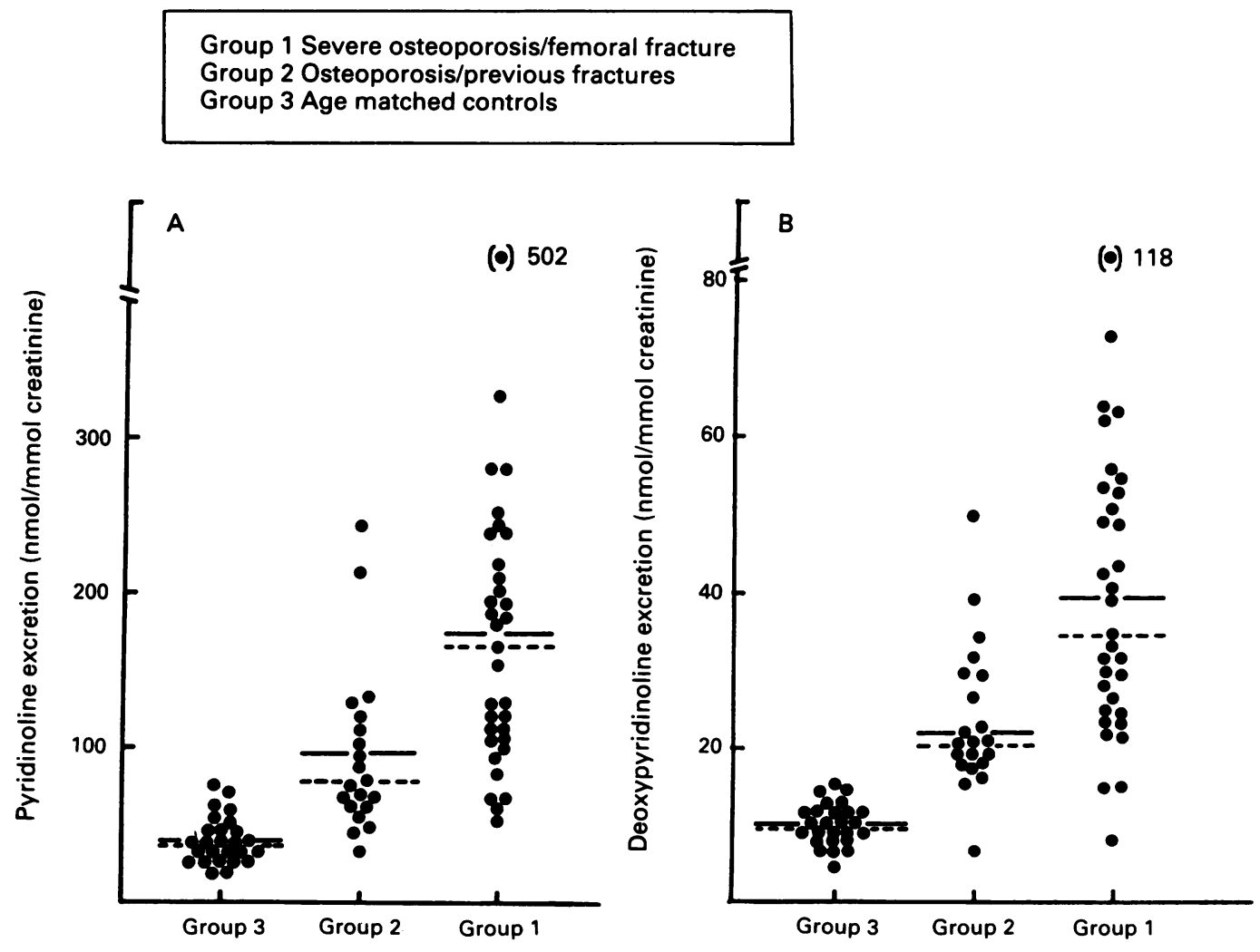

Values for the urinary excretion of the puridinium crosslinks, $(A)$ pyridinoline and $(B)$ deoxypyridinoline, relative to creatinine for subjects in two groups of osteoporotic patients compared with control subjects matched for age. The solid and broken lines indicate mean and median values, respectively. For further details see under Patients and methods. 
Table 2 Excretion of hydroxypyridinium crosslinks (Pyd=pyridinoline; Dpd= deoxypyridinoline) in urine from patients with recent femoral fractures who had had an operation compared with those without an operation. Values are mean $(S D)$ expressed relative to creatinine

\begin{tabular}{llll}
\hline $\begin{array}{l}\text { Group } \\
\text { of patients }\end{array}$ & $\begin{array}{l}\text { Mean }(S D) \text { concentration } \\
(\text { nmol/mmol creatinine })\end{array}$ & \multicolumn{1}{l}{$\begin{array}{l}\text { Pyd/Dpd } \\
\text { ratio }\end{array}$} \\
\cline { 2 - 3 } & Pyd & Dpd & \\
\hline $\begin{array}{l}\text { Patients with an operation }(\mathrm{n}=15) \\
\text { Patients without an operation }(\mathrm{n}=12)\end{array}$ & $172 \cdot 1(111 \cdot 3)$ & $\begin{array}{l}38 \cdot 4(25 \cdot 6) \\
173 \cdot 2(67 \cdot 2)\end{array}$ & $\begin{array}{l}4 \cdot 5(1 \cdot 0) \\
4 \cdot 3(1 \cdot 0)\end{array}$ \\
\hline
\end{tabular}

Table 3 Excretion of hydroxypyridinium crosslinks (Pyd=pyridinoline; Dpd= deoxypyridinoline) in urine from patients with accidental bone fractures compared with healthy control subjects matched for age and sex

\begin{tabular}{|c|c|c|c|c|}
\hline \multirow[t]{2}{*}{$\begin{array}{l}\text { Group } \\
\text { of patients }\end{array}$} & \multirow{2}{*}{$\begin{array}{l}\text { Mean age } \\
\text { (years) } \\
\text { (range) }\end{array}$} & \multicolumn{2}{|c|}{$\begin{array}{l}\text { Mean }(S D) \text { concentration } \\
(\text { nmol/mmol creatinine })\end{array}$} & \multirow[t]{2}{*}{$\begin{array}{l}\text { Pyd/Dpd } \\
\text { ratio }\end{array}$} \\
\hline & & Pyd & $D p d$ & \\
\hline Patients with accidental bone fracture $(n=15)$ & $\begin{array}{l}30 \cdot 7 \\
(20-49)\end{array}$ & $89 \cdot 3(20 \cdot 5)$ & $22 \cdot 8(4 \cdot 0)$ & $3.9(1.2)$ \\
\hline Healthy control subjects $(n=63)$ & $\begin{array}{l}31 \cdot 4 \\
(21-40)\end{array}$ & $22 \cdot 9(9 \cdot 9)$ & $6.59(3.4)$ & $3.8(1 \cdot 3)$ \\
\hline
\end{tabular}

\section{Discussion}

This study has shown large increases in the concentrations of pyridinoline and deoxypyridinoline in urine samples from patients with osteoporosis and osteoporotic fractures, which is indicative of increased rates of bone resorption. The fact that there was, however, no difference in the molar ratio, pyridinoline/ deoxypyridinoline, between the patient groups supports the view that the major part of the crosslinks in urine are derived from bone. This ratio was also similar to the pyridinoline/ deoxypyridinoline ratio in bone collagen, ${ }^{21}$ which is usually in the range three to four. Although pyridinoline is present in other tissues such as cartilage and tendon, these tissues apparently contribute little to the excretion of pyridinoline, probably because of the low turnover rates under normal conditions. In patients with active rheumatoid arthritis, a significant increase in the pyridinoline/deoxypyridinoline ratio compared with control subjects was noted, but this may be associated with a rapid turnover of synovial tissue which contains pyridinoline. ${ }^{17}$ Alterations in the pyridinoline/deoxypyridinoline ratio could also arise from changes in the relative concentrations of these components in bone, such as those that may occur in high turnover bone disease. ${ }^{19}$

In the patients with femoral neck fractures, a considerable proportion of the increased excretion of crosslinks in urine samples appeared to result from the fracture, as values for this group were significantly higher than those for the group without recent fracture. There was, however, considerable discrimination between the latter group and the control subjects matched for age, with about a twofold difference in the median values.

Patients with accidental fractures also had increased concentrations of pyridinium crosslinks in their urine, although there is at present no evidence that the mechanisms inducing increased bone resorption are the same in the two groups. Studies of the relative rates of bone formation and resorption in these patient groups would help to resolve this question and would provide a measure of net bone loss. Increases in bone formation associated with bone remodelling after fracture have been determined using osteocalcin in serum samples, ${ }^{22}$ for which the values continued to increase up to two months after fracture. A study of patients undergoing orthopaedic surgery suggested, however, that initially osteocalcin in serum samples decreased after the operation. ${ }^{23}$ For femoral fractures, alkaline phosphatase levels in serum samples were shown to be increased after two weeks, but returned to normal within six to 12 months after fracture. ${ }^{24} 25$

The increased resorption of bone observed in patients with bone fractures may simply be associated with callus formation and the repair process. Alternatively, the fracture may release humoral factors which lead to a more generalised increase in bone turnover. Although much of the evidence for such factors has come mainly from patients with head and spinal injuries, and could therefore be of neural origin, ${ }^{26}$ recent animal experiments suggest that induced fractures cause generalised changes in bone metabolism, indicating the production of one or more circulating factors. ${ }^{27}$ If this were so in patients with fractures, part of the increase in markers of bone resorption could be explained as a general skeletal response rather than being derived solely from the repair process.

Large differences in the amounts of crosslinks excreted within the patient groups were observed. Although it was shown that operations can be excluded, the variation might have been because the urine samples were collected at different stages of osteoporosis or different times after fracture. There was a trend that excretion increased with time after fracture, but the data from this study were not sufficient for analysis of the time effect. Increased concentrations of pyridinium crosslinks in urine were observed in patients up to eight weeks after discetomy operations, which was probably due to increased bone turnover after fracture during the operation (Ettel, McLaren, Seibel and Robins, unpublished results). A similar time dependent repair process might have occurred for these patients.

This study shows that measurements of the pyridinium crosslinks provide sensitive indices of bone resorption and that pyridinoline and deoxypyridinoline in urine are generally derived from bone. These assays therefore appear to have potential as part of a programme for monitoring bone loss and assessing the risk of fracture. Any such programme should, of course, also include measurements of the bone formation rate to allow distinctions to be drawn between situations where there is balanced high turnover and those where a net loss of bone occurs. The results also show that fractures have a marked and prolonged effect on the excretion of crosslinks which must be taken into account in the clinical application of these methods.

We thank Dr Carol Astbury and Miss Susan Dimmock for the preparation and processing of samples, and the orthopaedic preparation and processing of samples, and the orthopaedic
surgeons of Leeds General Infirmary for access to their patients. Surgeons of Leeds General Infirmary for access to their patients.
We are indebted to the Arthritis and Rheumatism Council for financial support. 
1 Kivirikko K I. Urinary excretion of hydroxyproline in health and disease. Int Rev Connect Tissue Res 1970; 5: 93-163.

2 Kelleher P C. Urinary excretion of hydroxyproline, hydroxylysine and hydroxylysine glycosides by patients with Paget's disease of bone and carcinoma with metastases in bone. Clin Chim Acta 1979; 92: 373-9.

3 Christiansen C, Riis B J, Rodbro P. Prediction of rapid bone loss in postmenopausal women. Lancet 1987; i: 1105-8.

4 Segrest J P, Cunningham $L$ W. Variations in human urinary $O$-hydroxylysyl glycoside levels and their relationship to collagen metabolism. F Clin Invest 1970; 49: 1497-509.

5 Krane S M, Kantrowitz F G, Byrne M, Pinnell S R, Singer $F$ R. Urinary excretion of hydroxylysine and its glycosides F $R$. Urinary excretion of hydroxylysine and its glycosides as an index

6 Robins S P. Turnover and crosslinking of collagen. In: Weiss J B, Jayson M I V, eds. Collagen in health and disease. Edinburgh: Churchill Livingstone, 1982: 160-78.

7 Fujimoto D, Moriguchi T, Ishida T, Hayashi $H$. The structure of pyridinoline, a collagen crosslink. Biochem Biophys Res Commun 1978; 84: 52-7.

8 Robins S P. Crosslinking of collagen: isolation, structural characterization and glycosylation of pyridinoline. Biochem f 1983; 215: 167-73.

9 Ogawa T, Ono T, Tsuda M, Kawanashi Y. A novel fluor in insoluble collagen: a crosslinking molecule in the collagen molecule. Biochem Biophys Res Commun 1982; 107: 1252-7.

10 Eyre D R, Koob T J, Van Ness K P. Quantitation of hydroxypyridinium crosslinks in collagen by highperformance liquid chromatography. Anal Biochem 1984; 137: 380-8.

11 Robins S P, Duncan A. Pyridinium crosslinks of bone collagen and their location in peptides isolated from rat femur. Biochim Biophys Acta 1987; 914: 233-9.

12 Gunja-Smith Z, Boucek R J. Collagen crosslink components in human urine. Biochem $\mathcal{F} 1981$; 197: 759-62.

13 Robins S P. An enzyme-linked immunoassay for the collagen crosslink, pyridinoline. Biochem $\mathcal{F}$ 1982; 207: 617-20.

14 Black D, Duncan A, Robins S P. Quantitative analysis of the pyridinium crosslinks of collagen in urine using ion-paired reversed-phase high-performance liquid chromatography. Anal Biochem 1988; 169: 197-203.

15 Robins S P, Stewart P, Astbury C, Bird H A. Measurement of the crosslinking compound, pyridinoline, in urine as an index of collagen degradation. Ann Rheum Dis 1986; 45 ; 969-73.

16 Black D, Marabani M, Sturrock R D, Robins S P. Urinary excretion of the hydroxypyridinium crosslinks of collagen in patients with rheumatoid arthritis. Ann Rheum Dis 1989; 48: $641-4$.

17 Seibel M J, Duncan A, Robins S P. Urinary hydroxypyridinium crosslinks provide indices of cartilage and bone involvement in arthritic diseases. $\mathcal{F}$ Rheumatol 1989; 16: 964-70.

18 Uelbelhart D, Gineyts E C, Chapny M-C, Delmas P D. Urinary excretion of pyridinium crosslinks: a new marker of bone resorption in metabolic bone disease. Bone Miner 1990; 8: 87-96.

19 Robins S P, Black D, Paterson C R, Reid D M, Duncan A Seibel M J. Evaluation of urinary hydroxypyridinium crosslink measurements as resorption markers in metabolic bone diseases. Eur $\mathcal{X}$ Clin Invest. 1991; 21: 310-5.

20 Folin A, Wu T. Determination of creatiine. In: Hawk H B, Oser B L, Summerrson W H, eds. Practical physiological chemistry. New York: McGraw-Hill, 1965: 506-8.

21 Eyre D R, Dickson I R, Van Ness K P. Collagen crosslinking in human bone and cartilage: age-related changes in the content of mature hydroxypyridinium residues. Biochem $\mathcal{J}$ 1988; 252: 495-500.

22 Obrant K J, Merle B, Bejui J, Delmas P D. Serum bone-gla protein after fracture. Clin Orthop Rel Res 1990; 258: 300-3.

23 Borsalino G, Borzoni R, Caravaggio F, et al. Variazion dell'osteocalcina sierica dopo interventi di chirurgia ortopedica. GClin Med 1985; 66: 393-400.

24 Nilsson B E, Westlin N E. The plasma concentration of alkaline phosphatase, phosphorus and calcium following femoral neck fracture. Acta Orthop Scand 1972; 43: 504-10.

25 Hordon L D, Peacock M. Vitamin D metabolism in women with femoral neck fracture. Bone Miner 1987; 2: 413-26.

26 Bidner S M, Rubins I M, Desjardins J V, Zukor D J, Goltzman D. Evidence for a humoral mechanism for enhanced osteogenesis after head injury. $\mathcal{F}$ Bone foint Surg. [Am] 1990; 72: 1144-9.

27 Einhorn T A, Simon G, Devlin V J, Warman J, Sidhu S P S Vigorita $\mathrm{V} J$. The osteogenic response to distant skeletal injury. F Bone foint Surg [Am] 1990; 72: 1374-8. 